\title{
The impact of atmospheric Rossby waves and cyclones on the Arctic sea ice variability
}

\author{
Marte G. Hofsteenge · Rune G. Graversen · Johanne H. Rydsaa · Zoé \\ Rey
}

Received: date / Accepted: date

Abstract The Arctic sea-ice extent has strongly declined over recent decades. A large inter-annual variability is superimposed on this negative trend. Previous studies have emphasised a significant warming effect associated with latent energy transport into the Arctic region, in particular due to an enhanced greenhouse effect associated with the convergence of the humidity transport over the Arctic. The atmospheric energy transport into the Arctic is mostly accomplished by waves such as Rossby waves and cyclones. Here we present a systematic study of the effect on Arctic sea ice of these atmospheric wave types. Through a regression analysis we investigate the coupling between transport anomalies of both latent and dry-static energy and sea-ice anomalies. From the state-of-the-art ERA5 reanalysis product the latent and dry-static transport over the Arctic boundary $\left(70^{\circ} \mathrm{N}\right)$ is calculated. The transport is then split

M. G. Hofsteenge

School of Geography, University of Otago, Dunedin, New Zealand

Department of Physics and Technology, UiT The Arctic University of Norway, Tromsø, Norway, Orcid ID: 0000-00015369-5318 E-mail: marte.hofsteenge@postgrad.otago.ac.nz

Rune G. Graversen

Department of Physics and Technology, UiT The Arctic University of Norway, Troms $\varnothing$, Norway

Norwegian Meteorological Institute,Troms $\varnothing$, Norway

Johanne H. Rydsaa

Department of Physics and Technology, UiT The Arctic University of Norway, Troms $\varnothing$, Norway, Orcid ID: 0000-00020538-0714

Zoé Rey

Department of Physics and Technology, UiT The Arctic University of Norway, Troms $\varnothing$, Norway into transport by planetary and synoptic-scale waves using a Fourier decomposition. The results show that latent energy transport as compared to that of drystatic shows a much stronger potential to decrease sea ice concentration. However, taking into account that the variability of dry-static transport is of an order of magnitude larger than latent, the actual impact on the sea ice appears similar for the two components. In addition, the energy transport by planetary waves causes a strong decline of the sea ice concentration whereas the transport by synoptic-scale waves shows only little effect on the sea ice. The study emphasises the importance of the large-scale waves on the sea ice variability.

Keywords Arctic sea ice, atmospheric energy transport, Rossby waves, cyclones, wave decomposition, Arctic climate

\section{Introduction}

The fast decrease in Arctic sea ice extent is one of the clearest indicators of the ongoing global warming due to anthropogenic greenhouse gas emissions (Fox-Kemper et al., 2021). Passive microwave satellite records from 1978 and onwards show significant trends of a decreasing sea-ice extent for every month of the year, with September showing the strongest decrease (Serreze and Stroeve, 2015). Superimposed on this decreasing trend is a large inter-annual variability. As of today, the recordlow sea-ice extent during the observational period was reached at the end of summer of 2012, although the 2020 September extent of only 3.92 million square kilometers was 2.49 million square kilometers below the 1981 to 2010 average, and was close to break the 2012 record. 
Several processes and mechanisms have been suggested to be important for the sea-ice variability, such as those induced by radiative effects related to surface albedo (Kashiwase et al., 2017), low-level clouds (Kay et al., 2008; Kay and L'Ecuyer, 2013; Liu and Schweiger, 2017), surface winds (Ogi et al., 2010; Zhang et al., 2013; Mills and Walsh, 2014), and oceanic (Årthun et al., 2012) and atmospheric (Kapsch et al., 2013; Park et al., 2015; Woods and Caballero, 2016; Wang et al., 2020) energy transport. Olonscheck et al. (2019) studied the contribution of different processes on the sea-ice variability based on experiments with the ECHAM6 climate model, eliminating processes one-by-one, and demonstrated that the sea-ice variability is mainly controlled by atmospheric temperature fluctuations induced by atmospheric energy transport or local ocean heat release, whereas variability of surface albedo, clouds, water vapour, surface winds, and ocean heat transport play a minor role. Previous studies have shown impact of atmospheric heat and moisture transport variability on the Arctic surface temperatures (Graversen, 2006; Woods et al., 2013; Baggett et al., 2016), and that e.g. cloud, humidity, and surface albedo are also modified by this transport (Graversen and Burtu, 2016; Liu and Schweiger, 2017; Graversen and Langen, 2019).

In addition, several studies have documented linkage between the mid-latitude atmospheric circulation and individual sea-ice events. A large sea-ice anomaly during summer of 2007 was encountered in the vicinity of the East-Siberian Sea, and was associated with anomalous atmospheric energy transport through the Pacific sector (Graversen et al., 2011). The warm and humid air that was advected into the Arctic resulted in anomalous longwave radiation and turbulent fluxes towards the surface in the area where the ice melt was encountered. Also the cloud-cover over the ice-melt area was affected (Schweiger et al., 2008). Another extreme year when it comes to Arctic summer sea-ice melt is, as mentioned above, 2012. It has been argued that this event was at least partly caused by an intense storm over the Arctic in the beginning of August that year (Simmonds and Rudeva, 2012; Zhang et al., 2013). Also during the winter season warm and humid advection from lower latitude appear to have a negative impact on sea-ice extent. March 2017 showed one of the lowest Arctic ice-extent levels for that month of the year since 1979, which is argued to be linked to episodes of increased warm and humid atmospheric transport from lower latitudes during the 2016-2017 autumn and winter season, which hampered the ice growth (Hegyi and Taylor, 2018).
Analysis including several years of data show that atmospheric circulation in spring is important for the development of the sea-ice over the summer. For years with a low September sea ice extent, an anomalous convergence of moisture transport over the Arctic in spring induces an enhanced greenhouse effect, which causes strong melt early in the melt season, which through the ice-albedo feedback can accelerate the melt over the summer (Kapsch et al., 2013, 2016; Yang and Magnusdottir, 2017). Also it has been suggested that preconditioning associated with unusual atmospheric circulation hampering ice growth in the cold season can effect seaice melt in the succeeding summer season, since under these circumstances the ice is already thinner at the beginning of the melt season (Döscher and Koenigk, 2013). Also variation in the onset of the Arctic melt season appears to be dependent on transport of moisture into the Arctic (Mortin et al., 2016), which affect the local cloudiness (Liu and Schweiger, 2017).

It has also been argued that short-lived synopticscale storm events in winter can cause large sea-ice retreats. The moisture that is brought into the Arctic by these storms strongly dampens the radiative cooling and the ice growth (Graham et al., 2019). In addition, ice growth is hampered due to snowfall from the storm events, since snow acts as an effective insulator, and the associated strong winds fracture ice and enhances ocean atmosphere heat exchange and lateral melt. Also Boisvert et al. (2016) noted that humid and warm air transported by cyclonic activity in winter of 2015-2016 led to decreased sea-ice conditions that winter. However, Screen et al. (2011) found that low cyclone activity in late spring and summer is linked to a reduced September sea-ice cover.

Hence, although it appears well documented that atmospheric circulation and its northward energy transport play an important role for the Arctic sea-ice variability, there is little consensus as to the role of the underlying circulation processes. Here we investigate the individual effect of large-scale planetary waves and synoptic-scale cyclones. Planetary waves have the potential to impact large part of the Arctic, whereas cyclones induce more local effects by nature. Earlier studies have indicated that planetary waves impact PanArctic temperatures more than do synoptic waves (Baggett 48 and Lee, 2015; Graversen and Burtu, 2016), which, as ${ }_{149}$ will be shown here, also is the case for the impact on ${ }_{150}$ sea ice.

From the state-of-the-art ERA5 reanalysis product ${ }^{153}$ we calculate atmospheric energy transport split into a ${ }^{154}$ 
dry-static and a latent energy component, where the latter is associated with the transport of water vapour. The latent component as compared to the dry-static has been shown to have a stronger impact on the Arctic surface-air temperatures per unit energy (Woods et al., 2013; Graversen and Langen, 2019). The transport can be further decomposed into planetary and synopticscale waves based on a Fourier decomposition (Graversen and Burtu, 2016). Planetary waves as compared to synoptic scale waves appear to have a stronger impact on Arctic climate (Baggett and Lee, 2015; Graversen and Burtu, 2016), although there is a strong interplay between the two components (Baggett et al., 2016; Papritz and Dunn-Sigouin, 2020). We investigate here the relationship between the different transport components and sea ice anomalies using lagged regressions and composites of extreme transport events.

\section{Methods and data}

The study is focused on the transport of dry-static and latent energy over the Arctic boundary, which is defined here as the $70^{\circ} \mathrm{N}$ latitude. We use the state-of-the-art ERA5 (Hersbach et al., 2020) reanalysis products with a 0.5 degrees horizontal spatial resolution, 137 vertical hybrid levels, and 6-hourly time resolution for the period 1979-2018. Due to a mass-inconsistency of reanalysis data (Trenberth, 1991), a barotropic mass-flux correction has been applied to the wind fields at each 6hourly time prior to the calculation of the energy transports (Graversen, 2006).

\subsection{Decomposition of the atmospheric energy transport}

Based on this reanalysis product, both the zonally and vertically integrated dry-static and latent energy transport are calculated as,

$v D(\phi)=\oint \int_{0}^{p_{s}} v\left(c_{p} T+g z+\frac{1}{2} \mathbf{v}^{2}\right) \frac{d p}{g} d x$

and

$v Q(\phi)=\oint \int_{0}^{p_{s}} v L q \frac{d p}{g} d x$,

respectively, where $\phi$ is latitude, $\mathbf{v}=(u, v)$ the zonal and meridional wind components, $c_{p}$ the specific heat capacity at constant pressure, $T$ temperature, $g$ gravity, $p$ pressure, $p_{s}$ surface pressure, $L$ the latent heat of condensation and $q$ specific humidity.

The transport can be further split into transport by planetary and synoptic-scale waves using a Fourier decomposition (Graversen and Burtu, 2016; Heiskanen et al., 2020). The decomposition is performed by applying a Fourier transformation of $v \frac{d p}{g},\left(c_{p} T+g z+\mathbf{v}^{2} / 2\right)$, and $L q$ before taking the zonal and vertical integrals. For $L q$ the transformation gives:

$L q=\frac{a_{0}^{L}}{2}+\sum_{n=1}^{\infty}\left\{a_{n}^{L} \cos \left(\frac{n 2 \pi x}{d}\right)+b_{n}^{L} \sin \left(\frac{n 2 \pi x}{d}\right)\right\}$,

where $d=2 \pi R \cos (\phi), R$ is the Earth's radius, $\phi$ latitude, $\mathrm{n}$ the zonal wave number. The Fourier coefficients $a_{n}^{L}$ and $b_{n}^{L}$ are given as:

$a_{n}^{L}=\frac{2}{d} \oint L q \cos \left(\frac{n 2 \pi x}{d}\right) d x$

and

$b_{n}^{L}=\frac{2}{d} \oint L q \sin \left(\frac{n 2 \pi x}{d}\right) d x$,

respectively, where $a_{n}^{L}$ and $b_{n}^{L}$ depend on latitude, height and time. Applying the Fourier transformation in a similar way to $v \frac{d p}{g}$ and $\left(c_{p} T+g z+\mathbf{v}^{2} / 2\right)$ allows for a decomposition of the transport into parts for different wave numbers. As suggested by Heiskanen et al. (2020), planetary waves are defined as wave numbers 1-3 and synoptic-scale waves numbers 4-20, as it was shown that this separation was most similar to a split between the two types of waves at $70^{\circ} \mathrm{N}$ applying an independent method based on a wavelet decomposition. This Fourier decomposition applied here is complete in the sense that the sum of the transport of waves 1-20 and the meridional transport, wave 0 , gives a negligible residual relative to the total transport (Graversen and Burtu, 2016).

A decomposition of the vertical integrated transport as a function of longitude in addition to latitude and time can be obtained by applying the Fourier decomposition only to the mass transport. For the latent transport of planetary and synoptic waves, this can be expressed:

\section{5} 97 98 99 200

201

02


(6)

$$
\begin{aligned}
& v Q_{S}(\lambda, \phi)= \\
& \sum_{k=1}^{N_{v}}\left\{\sum_{n \geq 4}\left[a_{n}^{v} \cos \left(\frac{n 2 \pi x}{d}\right)+b_{n}^{v} \sin \left(\frac{n 2 \pi x}{d}\right)\right] L q\right\},
\end{aligned}
$$

respectively, where $\lambda$ is longitude, and $a_{n}^{v}$ and $b_{n}^{v}$ are the Fourier coefficients for the mass flux, $v \frac{d p}{g}$, computed similar to Eqs. 4 and 5, respectively, and $N_{v}=137$ is the number of vertical levels in ERA5.

\subsection{Regressions}

In order to study the impact of the different transport components on the Arctic sea-ice extent, we perform a regression analysis of the sea-ice concentration (SIC) on the transport components. The ERA5 SIC data are based on the HadISST2.0.0.0 and OSI SAF SIC products (Hirahara et al., 2016). We use daily SIC data with a 1-degree spatial resolution. The annual cycle and the trend in the SIC data were removed by subtracting a 5 -year running mean climatology over the period from 1979 til 2018. The running mean was computed similar to Kapsch et al. (2019), where the first and last two years of the period are calculated as a weighted mean. By subtracting the running mean climatology this way, the long-term trend is removed even if not linear. The SIC anomalies including year-to-year variability are retained.

The seasonal cycle was removed from the transport data, to isolate the impact of transport anomalies. Transport data is not de-trended and a test with detrended data showed that this would not influence the regression coefficients we found. The energy transport influences sea ice through their effect on the surface energy components. Therefore surface energy fields including shortwave radiative, longwave radiative, sensible and latent heat fluxes are used from the ERA5 product, where positive values indicate downward fluxes. For the surface energy fields, trend and seasonal cycle are removed by subtracting a 5-year running-mean climatology, similarly as for the SIC data.

All regressions are calculated using the 40-years timeseries (1979-2018). The regressions are computed for different positive and negative time-lags, to find the statistical link of events occurring before and after each other. The regression coefficients are calculated as the Beta-coefficient of linear regression. To calculate the regression $(\mathrm{R})$ of $y$ on $x$, we use:

$\mathrm{R}=\frac{\sum(x-\bar{x})(y-\bar{y})}{\sum(x-\bar{x})^{2}}$

The significance of the regression coefficients are tested using a Monte Carlo approach. In this approach 5000 random time series were computed by applying a random phase shift to the Fast Fourier Transform of the time-series. This way of randomizing the data series makes sure that the artificial time-series has the same power spectrum as the original time-series. The regression coefficients that are calculated using the artificial time-series are then compared with the coefficients for the original data. We use a 95 and $99 \%$ significance level, meaning that when less than 5 and $1 \%$, respectively, of the artificial regression coefficients are numerically larger than the original regressions, the regression coefficient is considered significant.

\section{Results}

3.1 Impact of planetary and synoptic transport on Arctic sea ice

Atmospheric energy-transport by planetary waves leads to a decrease in Arctic sea-ice concentration (SIC). This is evident from the regressions of SIC on the dry-static and latent transport component (Fig. 1a and b). For positive time lag, transport by these wave types show significant negative regressions, meaning that planetary transport events are followed by a decrease in SIC.

The regression coefficients for the latent transport are clearly larger compared to those of the dry-static. This indicates that for anomalous transport events of similar magnitude, the latent transport has a considerably larger impact on the Arctic sea ice than its drystatic counterpart. This is in agreement with previous finding that the latent transport as compared to the dry-static affects the Arctic surface-air temperature more (Graversen and Burtu, 2016). The regression coefficients indicate that a latent transport anomaly by planetary waves of $1 \mathrm{PW}$ results in a decrease in sea ice area of about 0.22 million $\mathrm{km}^{2}$ around 4 days after the anomalous event. For an average Arctic sea-ice area of about 10 million $\mathrm{km}^{2}$ over the 40-year study period, this is a decrease of $2.2 \%$ of the ice area. The significant negative anomalies sustain for about 9 days after a dry-static transport event, but up to 30 days after 
a) Dry-static

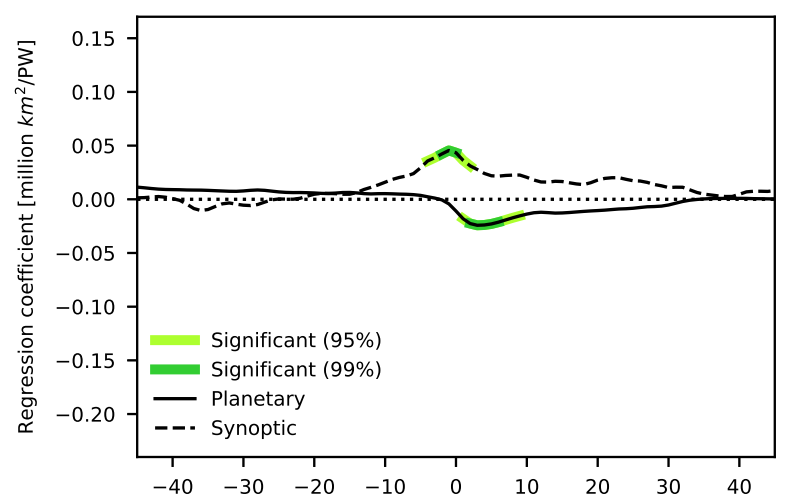

c) Dry-static scaled

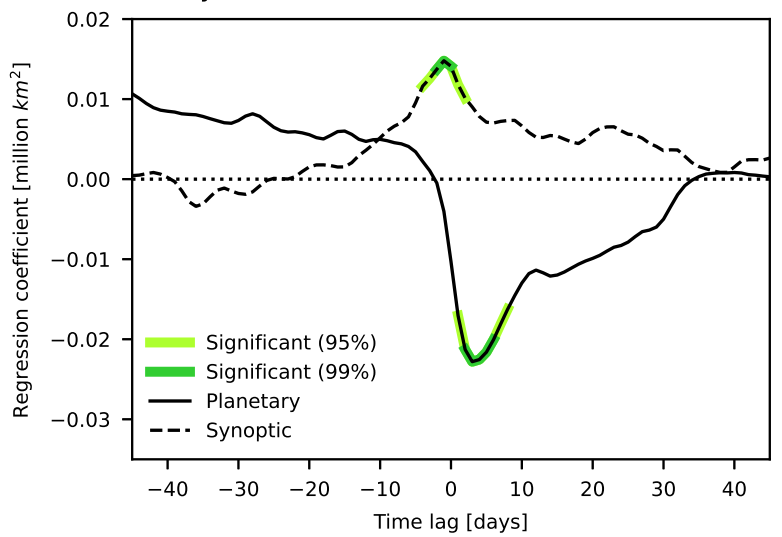

b) Latent

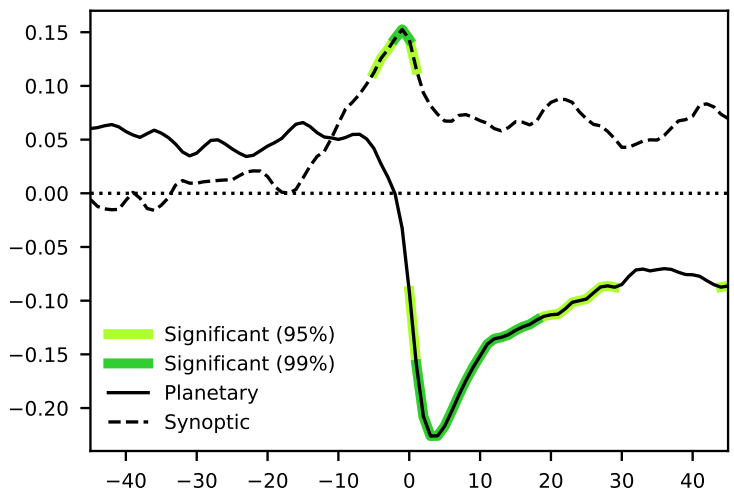

d) Latent scaled

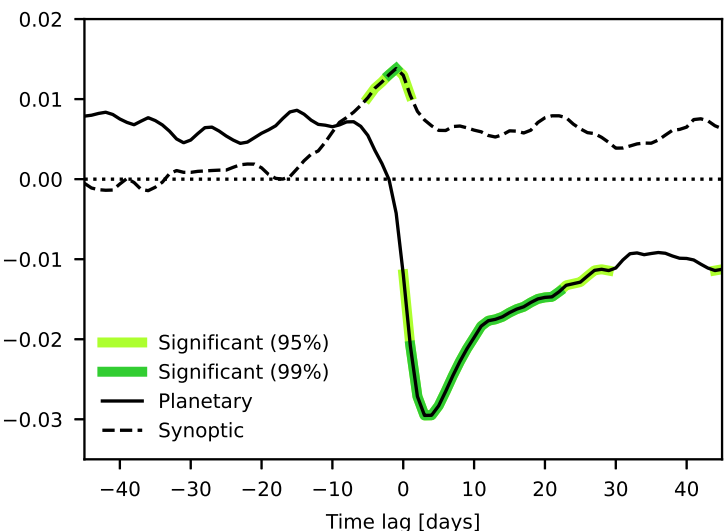

Fig. 1 Regressions of Arctic SIC on (a, c) dry-static and (b, d) latent atmospheric energy transport across $70{ }^{\circ} \mathrm{N}$, as a function of time lag. Regressions are given for both planetary and synoptic-scale waves, and are in units of Arctic SIC anomaly in million $\mathrm{km}^{2}$ per PW of transport. Frame $\mathrm{c}$ and $\mathrm{d}$ show the regression coefficients as in a and b but multiplied by the standard deviation of the transport. Hence these frames show the sea-ice change induced by a 1 standard deviation anomaly of the transport components across $70{ }^{\circ} \mathrm{N}$. Regressions significant on the 95 and $99 \%$ level are shown with light and dark green shading, respectively.

a latent event of the same magnitude. This is consistent with long-term impact that sea-ice anomalies may have through dynamic and radiative effects such as the ice-albedo feedback mechanism (Kashiwase et al., 2017; Graham et al., 2019).

Although the latent energy transport by planetary waves shows a considerably stronger potential to decrease Arctic sea ice than its dry-static counterpart, the two components appear to have similar sea-ice impact when the difference in variability is taken into account (Fig. 1c and d). The daily dry-static and latent transport by planetary waves across $70^{\circ} \mathrm{N}$ constitute in an annual mean about 1.5 and $0.3 \mathrm{PW}$, respectively, and their standard deviations are 0.94 and $0.13 \mathrm{PW}$, respectively. By scaling the regression coefficients by the standard deviation of the transport components, the actual impact on the sea ice of the different transport components can be compared.

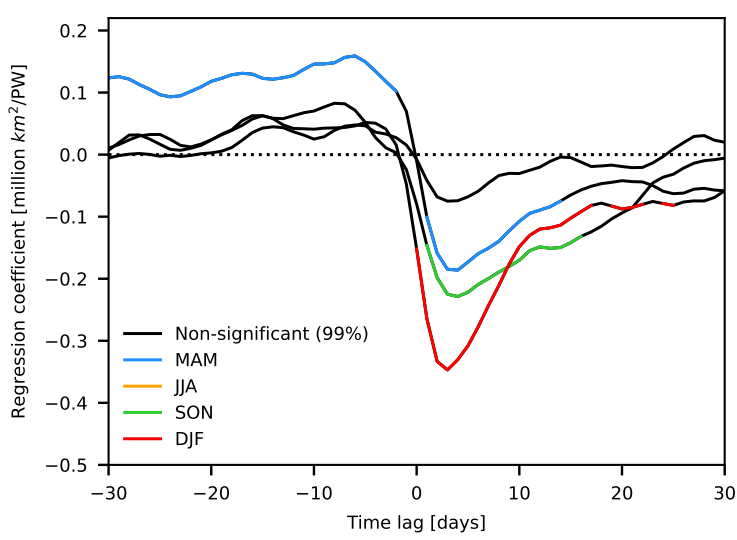

Fig. 2 As Fig. 1 but for seasonal regressions of Arctic SIC on the latent energy transport by planetary waves across 70 ${ }^{\circ} \mathrm{N}$ as a function of time lag. Regressions significant at the 99 $\%$ level are shown in color, while non-significant regressions are indicated in black. 
a) Dry-static

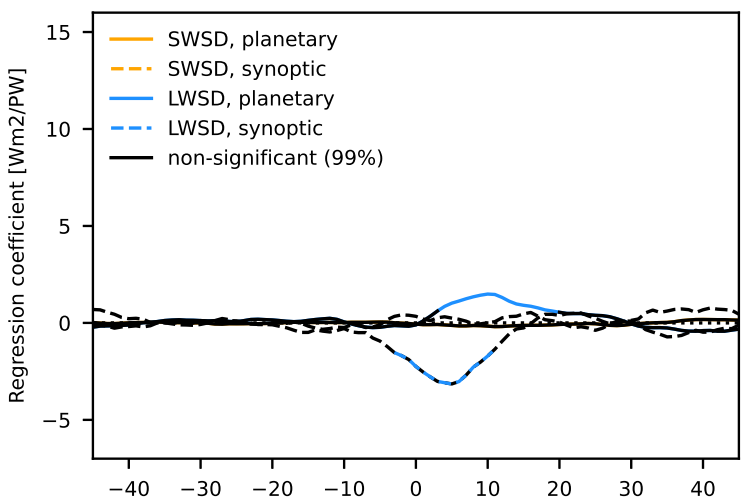

c) Dry-static scaled

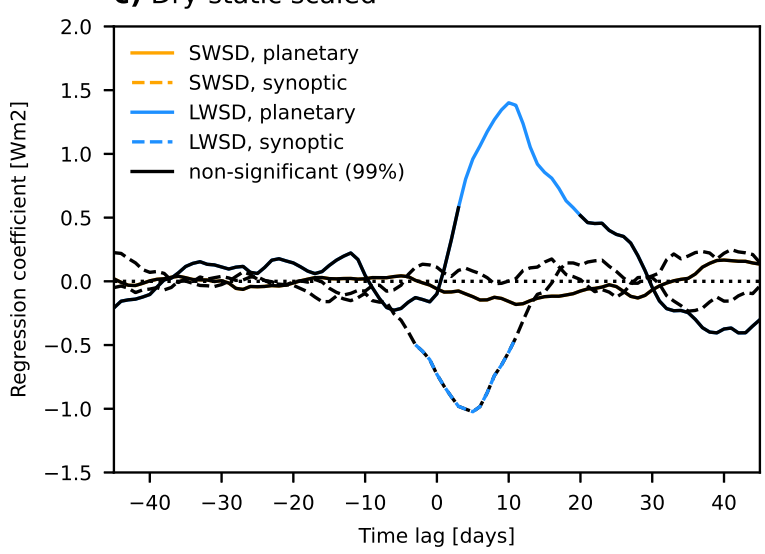

b) Latent

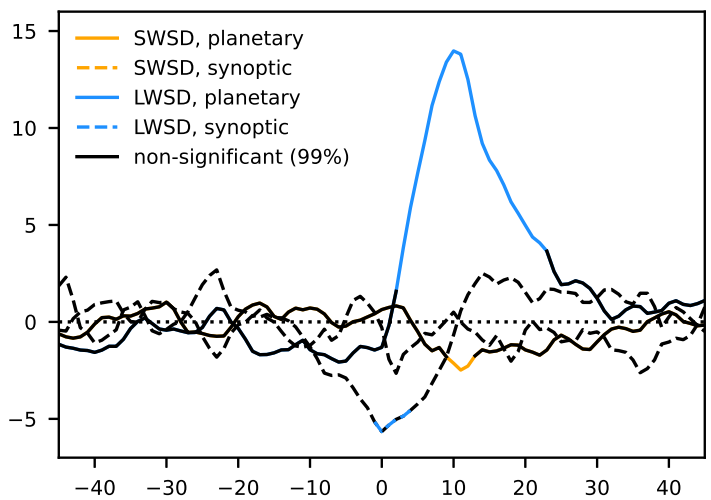

d) Latent scaled

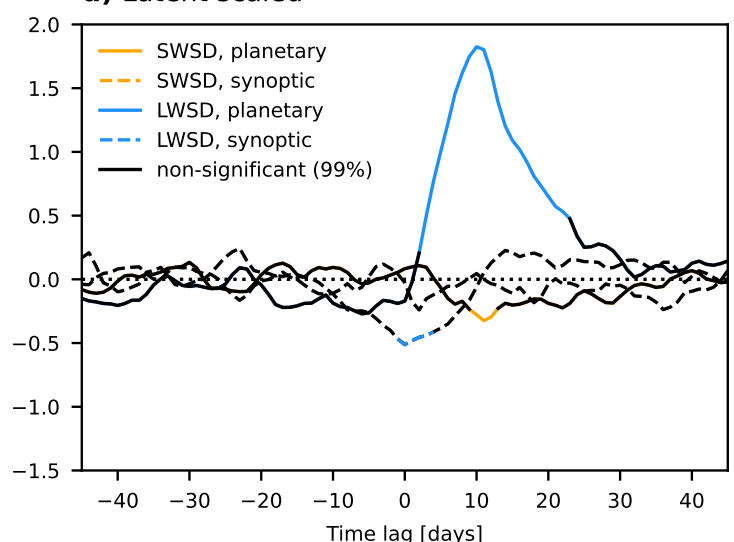

Fig. 3 As Fig. 1, but for the regressions over the Arctic sea-ice ( $>15 \%$ concentration) of shortwave (SWSD) and longwave (LWSD) downward radiation at the surface on the energy-transport components at $70^{\circ} \mathrm{N}$. Units are radiation anomalies in $\mathrm{W} / \mathrm{m}^{2}$ per PW of transport. Regressions significant at the $99 \%$ level are indicated in colour, and non-significant regressions in black.

The impact on Arctic SIC by synoptic-scale waves is considerably smaller and, in fact, opposite in sign as compared to that of the planetary waves (Fig. 1). Around lag zero, significant positive correlation coefficients are apparent for both the dry-static and latent synoptic-scale transport. The positive sea-ice anomalies around lag zero indicate cold Arctic conditions and hence an anomalously large meridional temperature gradient between mid and high latitudes which enhances baroclinicity in the Arctic boundary regions. These anomalous temperature contrasts strengthen the baroclinicity and growth of synoptic-scale waves at the Arctic boundary, which is likely leading to the positive anomalies of synoptic-scale waves. Hence the interpretation of cause and effect based on these lag-regression analyses becomes opposite for planetary and synoptic-scale waves: Where the lag-regressions reveal that SIC reduction follows energy transport by planetary waves, the positive zero-lag regressions for synoptic-scale waves are consistent with a cold Arctic leading to increase of synoptic- scale wave at the Arctic boundary due to enhanced baroclinicity. This interpretation is consistent with previous findings based on temperature regressions on the energy transport components (Graversen and Burtu, 2016).

The decrease in SIC after transport events by the planetary-wave latent energy transport is the strongest in the winter season (DJF; Fig. 2). The negative SIC impact is significant in all seasons except summer. The ice-edge region is the largest in winter and smallest in summer, and therefore the transport anomalies can impact sea ice in a larger area during the cold seasons than during summer. Note that all months show positive regressions indicating enhanced sea-ice extent prior to the transport event (at lag zero), although only in spring (MAM) these are significant. The increased sea-ice concentrations preceding the planetary transport events indicate that transport extremes tend to occur predomi- 
a) Dry-static

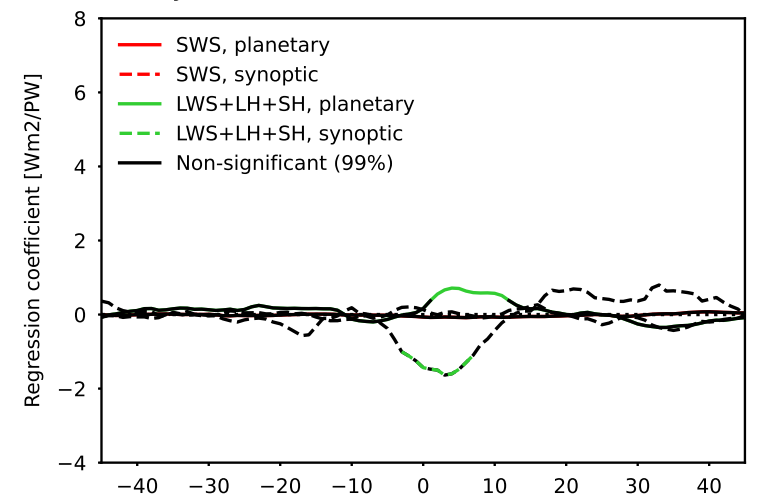

c) Dry-static scaled

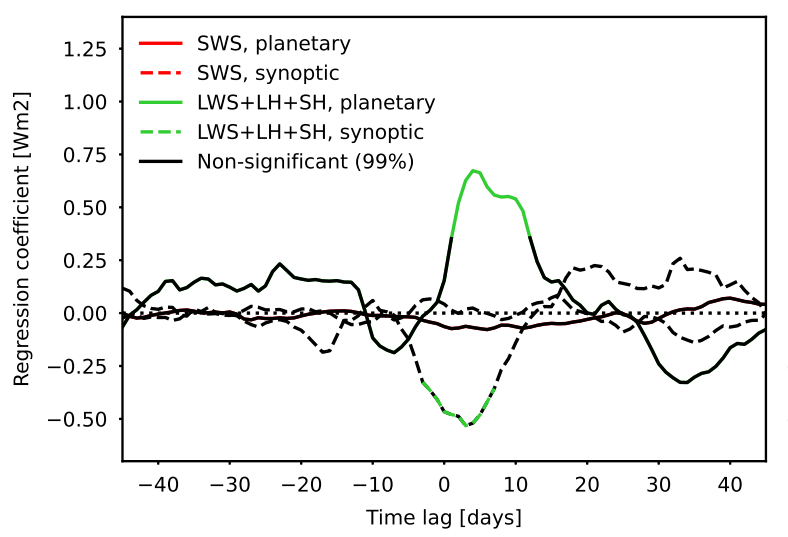

b) Latent

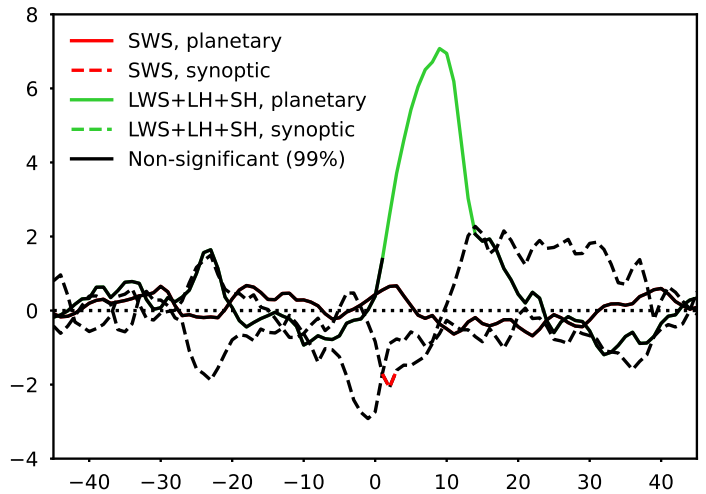

d) Latent scaled

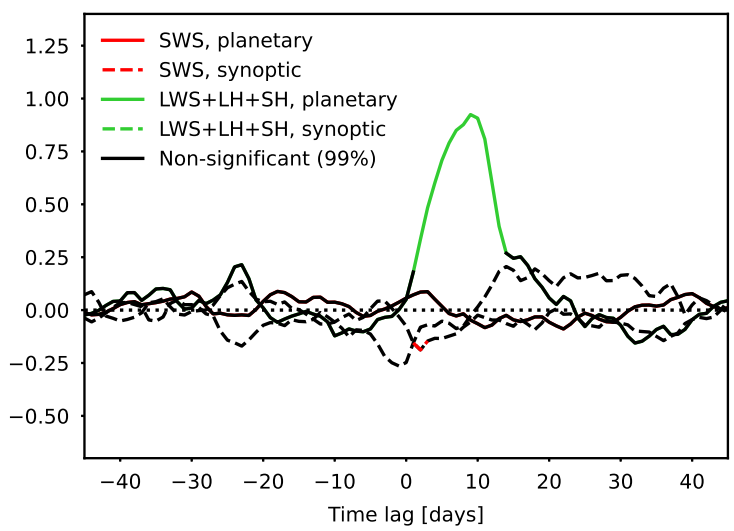

Fig. 4 As Fig. 1, but for the regressions over Arctic sea ice of net shortwave (SWS) and longwave (LWS) radiation plus turbulent fluxes of sensible $(\mathrm{SH})$ and latent $(\mathrm{LH})$ downward at the surface on the energy-transport components at $70{ }^{\circ} \mathrm{N}$. Units are radiation anomalies in $\mathrm{W} / \mathrm{m}^{2}$ per $\mathrm{PW}$ of transport. Regressions significant at the $99 \%$ level are indicated in colour, and non-significant regressions in black.

nantly during cold Arctic conditions.

Both dry-static and latent energy transport across $70^{\circ} \mathrm{N}$ lead to convergence of heat in the atmosphere over the Arctic, which is partly radiated and turbulently mixed to the surface. Hereby anomalous advection into the Arctic of the two transport components can induce anomalous energy flux to the surface, which may melt or hampers freeze up of sea ice. However, events of anomalous transport by the latent component have a much stronger potential to impact the sea ice because of the enhanced humidity and cloud formation that this transport component gives rise to (Graversen and Burtu, 2016), which considerably increases the radiation to the surface by the greenhouse effect. This is evident from regressions of downwelling longwave radiation (LWSD) on the two components of the planetary transport (Fig. 3a and b). These regressions show a significant increase of the LWSD after the transport events, which is considerably larger and last longer for the latent than for the dry-static component. Similar regressions for the downwelling shortwave radiation (SWSD) indicate negative values for the planetary latent transport at positive time lags consistent with an increase of the cloud cover succeeding events of this transport. After scaling the regressions with the standard deviation of the two transport components, to take into account that variability of the dry-static transport is an order of magnitude larger than that of the latent, the actual impact on the downwelling longwave radiation of the two transport components appear similar (Fig. 3c and d).

Similar to the regression of the planetary-scale transport, regressions of LWSD on the synoptic-scale transports show positive values for positive time lag, although these regressions are smaller than those of the planetary-scale transport and not significant. However, significant but negative regressions are found for the synoptic transport dry-static component around lag zero. 
a) Dry-static

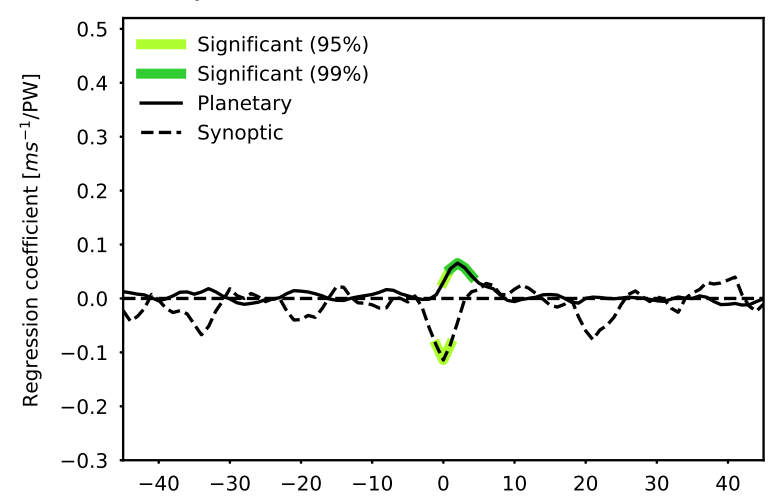

c) Dry-static scaled

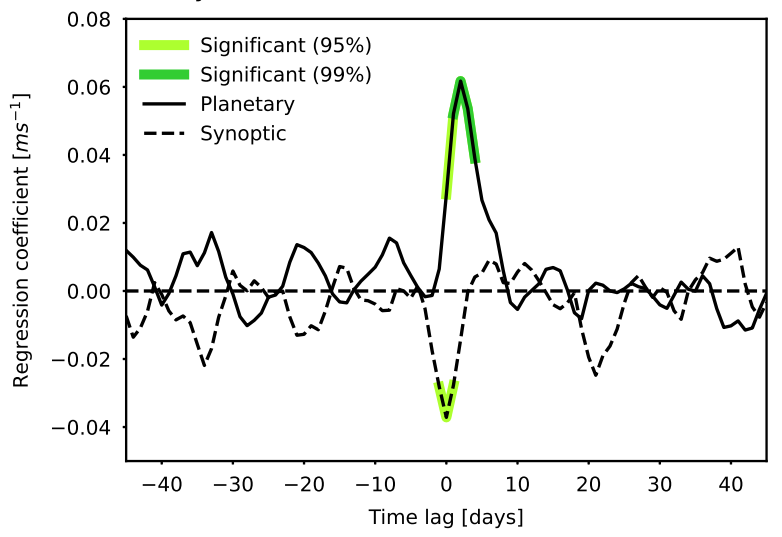

b) Latent

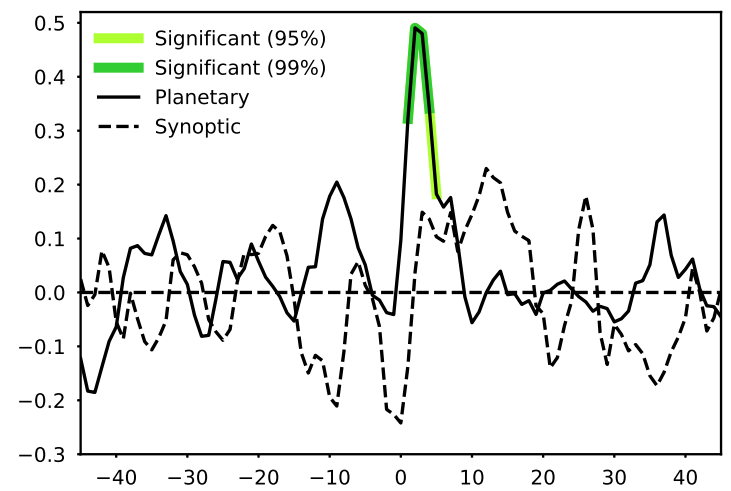

d) Latent scaled

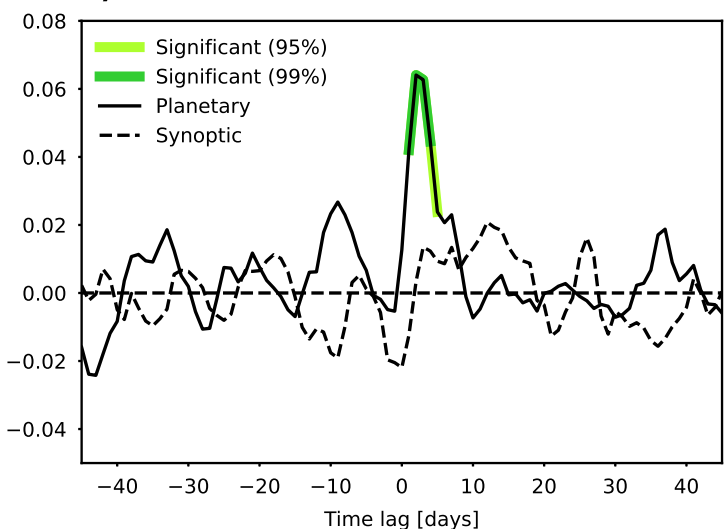

Fig. 5 As Fig. 1 but for the regressions over the Arctic sea-ice ( $>15 \%$ concentration) of $10 \mathrm{~m}$ wind speed on the energytransport components at $70^{\circ} \mathrm{N}$. Units are wind anomalies in $\mathrm{m} / \mathrm{s}$ per PW of transport. Regressions significant at the $99 \%$ level are indicated in colour, and non-significant regressions in black.

This is again consistent with the discussion above that enhanced cyclogenesis leading to a positive anomaly of the synoptic-scale waves, is associated with anomalously cold Arctic conditions with a cold atmosphere radiating less than usual to the surface.

The increase in downwelling longwave radiation at the surface following planetary events may lead to a surplus of energy at the surface causing ice melt or reduced ice growth. This is supported from regressions of the total surface net longwave radiation plus turbulent fluxes on the transport components (Fig. 4). The sum of net longwave radiation and turbulent fluxes constitutes the major part of the surface energy fluxes. A surplus of energy is found following planetary transport events, which is consistent with the ice reduction during the same period (Fig. 1). The net shortwave radiation is the remaining part that in conjunction with the net longwave radiation plus turbulent fluxes constitute the total energy transfer to the surface from the atmosphere. However this component is little affected by the transport anomalies.

Consistent with the discussion above, scaling of the transport components with their variability indicates that dry-static and latent planetary transport have a similar impact on the surface-energy balance over the Arctic, and that synoptic-scale wave events appear associated with an anomalously negative surface-energy balance and positive sea-ice anomalies (Fig. 1).

In addition to thermodynamic effects, as shown by Fig. 4, the mass flow associated with the transports may also directly impact sea ice due to friction. Increase in $10 \mathrm{~m}$ winds over the sea ice is succeeding events of planetary-wave transport of both dry-static and latent energy (Fig. 5). The impact per PW of transport is much stronger for the latent than for the dry-static component (Fig. 5a and b), since a given mass flow potentially can transport far more energy of the drystatic than of the latent type, and hence the mass flow has to be considerably stronger to transport the same 
amount of energy in the latent than in the dry-static form. Again, when the two transport components are scaled by the standard deviation, the wind impact becomes similar (Fig. 5c and d). Note that the duration of the dynamical impact of the planetary-scale waves is shorter than that related to thermodynamic effect associated with anomalous surface-energy imbalance. Hence the response of the Arctic atmosphere to a transport anomaly seems to stay for another 1-2 weeks after the flow anomaly has relaxed.

For the synoptic-wave transport, the wind anomalies associated with this transport at around lag zero are negative though not significant for the latent part. This is indicating that the atmosphere over the Arctic sea ice is anomalously little affected by advection and hence left to adiabatic cooling consistent sea-ice grow and in line with the discussion above.

\subsection{Regions of high sea-ice variability}

We continue by focusing on two regions that show large sea-ice variability, both on the annual and year-to-year time scales: the Chukchi and East-Siberian Sea and the Barents and Kara Sea regions (Kapsch et al., 2013; Parkinson and Cavalieri, 2008; Peng and Meier, 2018). The former region contributes $22 \%$ of the summer seaice variability of the Arctic (Onarheim et al., 2018), and is also the region of the largest ice retreat during the 2007 September sea-ice minimum; an event caused by an anomalous flow of warm and humid air into that region (Graversen et al., 2011). The latter region accounts for the largest fraction of ice variability in March (27 $\%$, Onarheim et al. (2018)). We will here focus on the latent energy transport, as our previous results showed that this type of transport has a much larger potential than the dry-static to decrease the Arctic SIC.

The ice concentration in the Barents and Kara Seas is impacted significantly by the planetary wave latent transport. This is evident in Fig. 6a, showing negative regressions for positive time lags, with a maximum impact on the sea ice around 4 days after a transport event. Hence positive anomalies of the planetary waves cause significant ice reduction that last for more than 50 days after an event. The transport impact on sea ice is found in all season except summer when little ice is present in this region (Fig. 7). In the remaining seasons, the Barents and Kara Seas are part of the marginal ice zone, and the region is situated just north of the main gateway for transport events, which will be further discussed below. It has earlier been reported that Barents and Kara Seas have the largest SIC variability and
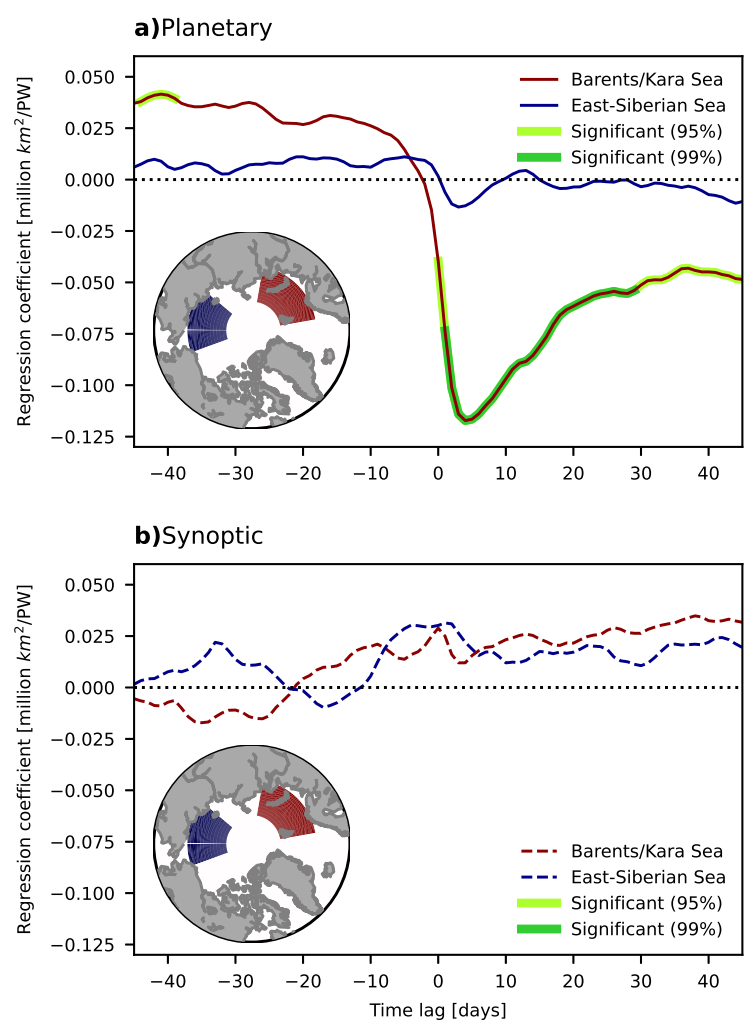

Fig. 6 Regressions of SIC in the Barents and Kara Seas (red) and Chukchi and East-Siberian Seas (blue) on the latent energy transport by (a) planetary and (b) synoptic-scale waves across $70^{\circ} \mathrm{N}$. Regressions are given as a function of time lag in units of SIC anomaly in million $\mathrm{km}^{2}$ per PW of transport. Regressions significant on a 95 and a $99 \%$ level are shown with light and dark-green shading, respectively.

trends in winter (Onarheim et al., 2018). The significant regressions for negative time lags in spring show a pre-conditioning effect: planetary transport events are more likely to occur in spring when initially there is more sea ice in the Barents and Kara Seas, and hence likely colder condition in this area and stronger temperature gradient towards the Atlantic sector.

In contrast to the Barents and Kara Seas, we find no significant impact on sea ice in the Chukchi and East-Siberian Seas (Fig. 6a). This weak impact may appear surprising given that this is a region where summer ice minima often occur. The Chukchi and EastSiberian Seas have played a major role in recent record years of low summer sea ice and for the overall negative sea-ice trend during this season (Kapsch et al., 2013). However, for example when it comes to the large sea-ice anomaly of 2007, which mainly appeared in this area, it was found that although warm and humid air from the Pacific played a major role, the zonal-mean transport was not particularly strong during this sea- 
a) MAM

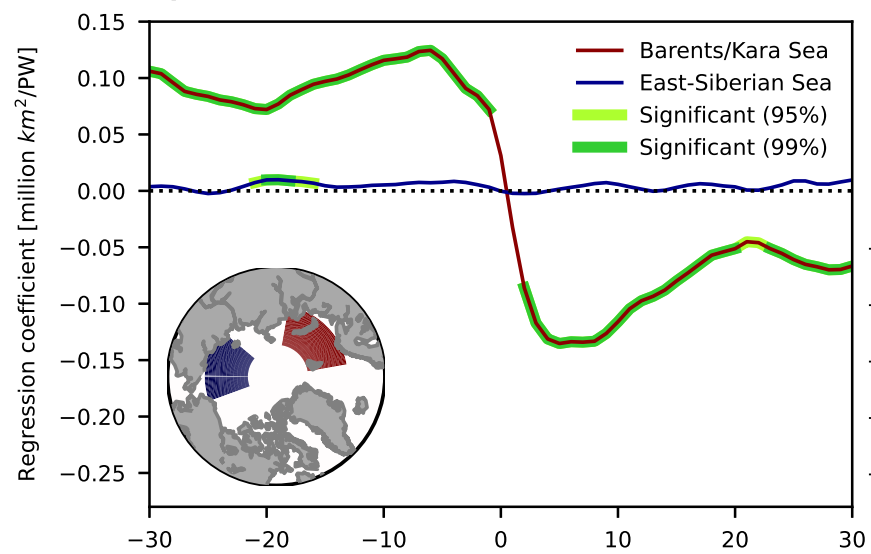

c) $\mathrm{SON}$

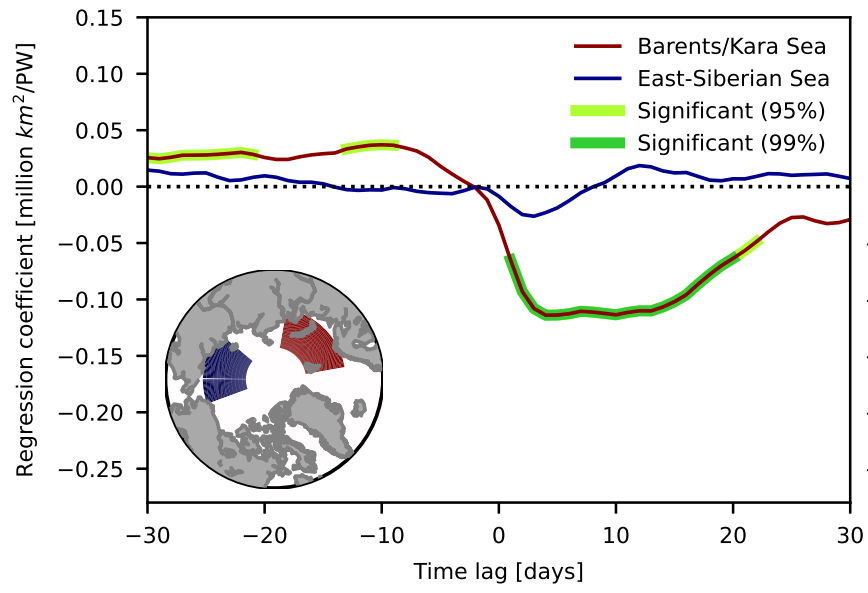

b) JJA

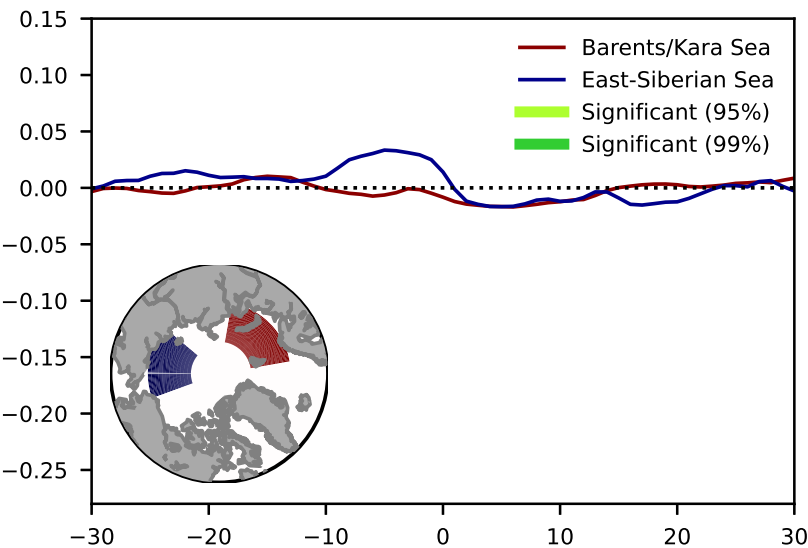

d) DJF

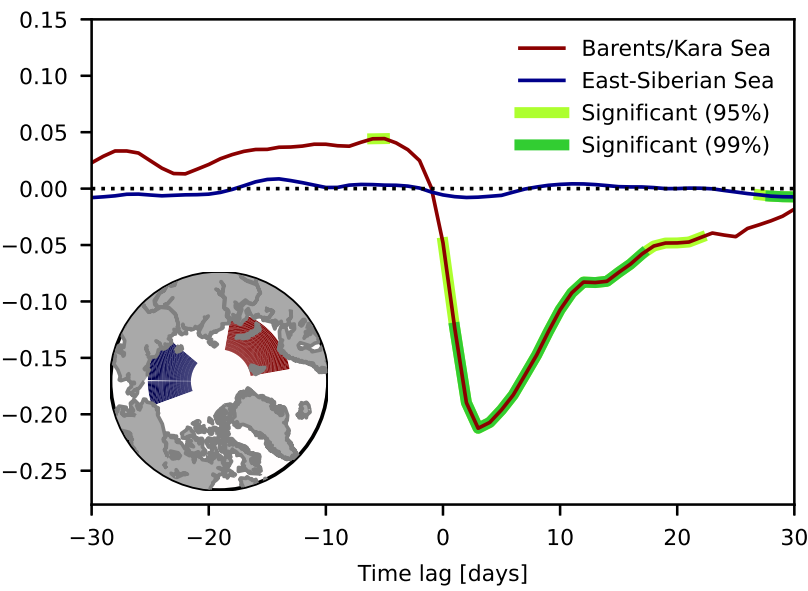

Fig. 7 As Fig. 6a but for a split into seasons, (a) March-May, (b) June-August, (c) September-November, and (d) DecemberFebruary.

ice minimum event (Graversen et al., 2011). Little or no impact is found from the synoptic wave transport in neither of the investigated regions (Fig. 6b).

\subsection{Atlantic and Pacific energy transport}

The analysis so far is based on regressions of SIC on the zonal-mean transport across $70{ }^{\circ} \mathrm{N}$. But as appeared from the summer-of-2007 anomaly (Graversen et al., 2011), the impact of atmospheric transport extremes on SIC might be depending on the longitude of the transport, and not on the zonal-averaged quantity. For this reason the transport is now split into Atlantic and Pacific-sector parts and the focus will be only on the latent transport by planetary waves as this component shows the largest sea-ice impact. The Atlantic and Pacific sectors are chosen following Rydsaa et al. (2021) finding that these sectors are dominating the transport when it comes to extreme events in the winter season.
These sectors encounter longitudes from $30{ }^{\circ} \mathrm{W}$ to 30 ${ }^{\circ} \mathrm{E}$ and from $145{ }^{\circ} \mathrm{W}$ to $160{ }^{\circ} \mathrm{E}$, respectively, and are also known for being dominant pathways for winter cyclones (Serreze et al., 1993; Zhang et al., 2004).

Indeed, when analyzing the transport over the Atlantic and Pacific sector separately, both the Barents and Kara Seas as well as the Chukchi and East-Siberian Sea region show a sea-ice decline after the transport events in the adjacent sector (Fig. 8). The ice reduction is consistent with enhanced thermodynamic surface forcing associated with a net surface imbalance of net longwave radiation and turbulent fluxes in favour of the surface, and to some extent dynamic forcing from increase in surface winds (Fig. 9). Moreover it appears that a transport event in one sector, having a negative impact on sea ice in the adjacent region, has a reverse impact on the other, remote region. This indicates a tendency of cross Arctic transport associated with 

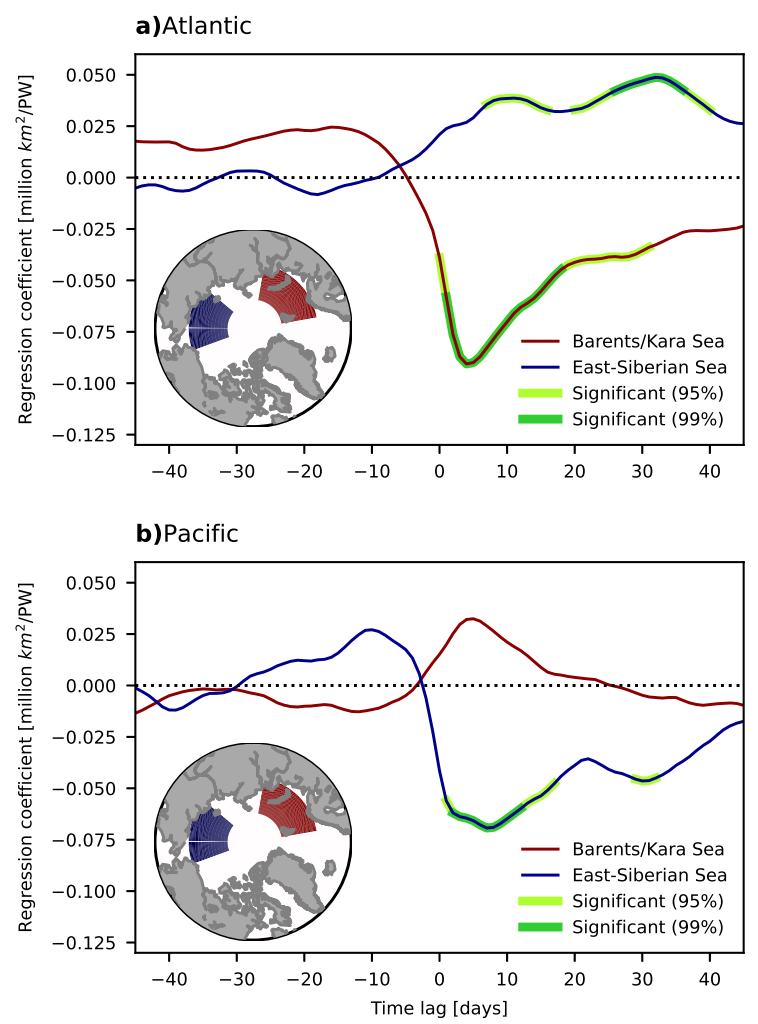

Fig. 8 Regressions of SIC in the Barents and Kara Seas (red) and Chukchi and East-Siberian Seas (blue) on the latent energy transport by planetary waves across $70^{\circ} \mathrm{N}$ over the Atlantic (a) and Pacific (b) sector. Regressions are given as a function of time lag, in units of SIC anomaly in million $\mathrm{km}^{2}$ per PW of transport. Regression significant on a 95 and $99 \%$ level are shown in light and dark-green shading, respectively.

the large planetary waves. Hence, a transport event up through the Atlantic sector causes winds and increase in surface energy flux over the Barents and Kara Seas, resulting in a negative sea-ice anomaly there, but a significant reduction in surface energy flux and positive ice anomaly over the Chukchi and East-Siberian Seas (Figs. 8 and 9), as likely the planetary-wave flow has cooled and dried on its path over the North Pole.

Following again Rydsaa et al. (2021), extreme events for the winter season are here presented in order to provide a quantitative example of the transport impact: Fig. 10 shows 5-day-lag composites of sea-ice and surface-wind anomalies that correspond to extreme latent planetary transport events in winter. Extreme events are defined as days when the zonal-mean transport anomalies are larger than the 97.5th percentile. Fig. 10a is for all events, with maximum transport occurring at any longitude at $70^{\circ} \mathrm{N}$, whereas Fig. 10b and c present extreme events occurring in the Atlantic and the Pacific sector, respectively.

For extreme latent planetary wave transport through the Atlantic sector, strong significant negative sea-ice anomalies are found in the Barents and Kara Seas, whereas positive anomalies appear south of the Bering Strait (Fig. 10b). This transport pattern is accompanied by anomalies of downwelling longwave radiation showing significantly positive anomalies north of the Atlantic sector towards the North Pole, but switching to significantly negative anomalies in the vicinity and south of the Bering Strait (Fig. 11a). In the vicinity of the Barents and Kara Seas, where the marginal ice zone is often encountered in winter, large part of the longwave radiation is absorbed by the surface causing ice melt or delaying freeze up, which is apparent from the significant positive anomaly of the net longwave radiation over this region (Fig. 11b). The positive energy balance in favour of the surface in this region is enhanced by reduction of latent and sensible turbulent fluxes (Fig. 11c and d).

Further to the north in the central Arctic, the sea-ice anomalies are much smaller as presumably here the ice is thicker and temperature lower. Hence even though these transport extremes induce increase in longwave radiation over the central Arctic, this excess in surface energy warms the surface rather than causes significant ice area changes, resulting in a corresponding increase in up-welling radiation and, as a consequence, little change in net radiation. Consistent with the ice showing little change in the central Arctic, also the turbulent surface fluxes remain little affected here during the extreme transport events. South of the Bering Strait, where the downwelling longwave radiation shows negative anomalies and the sea-ice cover increases, also the net longwave radiation anomaly is negative, indicating that the surface temperature stays about constant over this region during the freeze up.

Also surface wind anomalies associated with the trans- ${ }^{623}$ port extremes may play a role for the sea-ice response. $\quad{ }^{624}$ Over the ice-retreat area in the vicinity of the Barents and Kara Seas, anomalously strong winds from the south appear, which may break up ice into flows and cause leads and polynyas.

For the transport extremes in the Pacific sector, reduction of ice is found in the winter marginal ice zone south of the Bering Strait, and consistent with the Atlantic extremes, positive ice anomalies are found on the opposite site of the Arctic (Fig. 10c). When it comes to all extremes, their transport maxima are mostly con- 
a) Atlantic, LWS + SSH + SLH

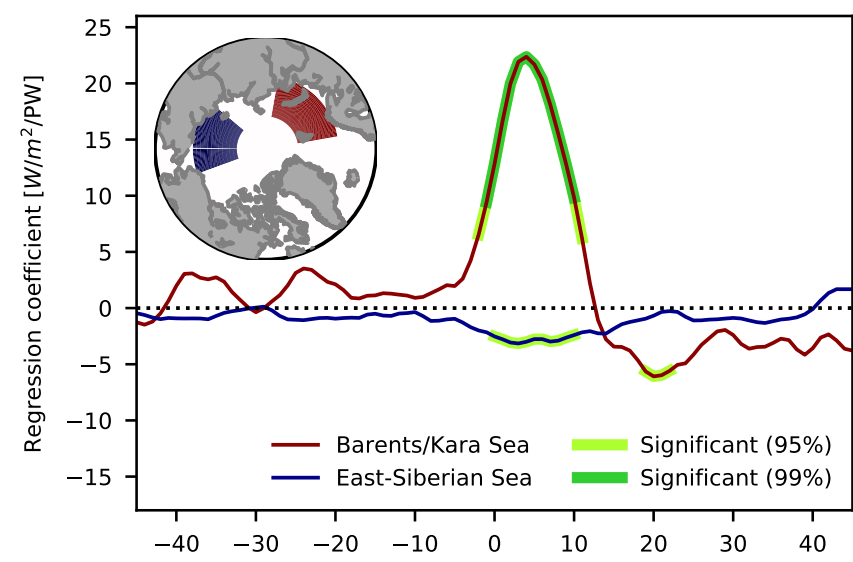

c) Atlantic, $10 \mathrm{~m}$ wind

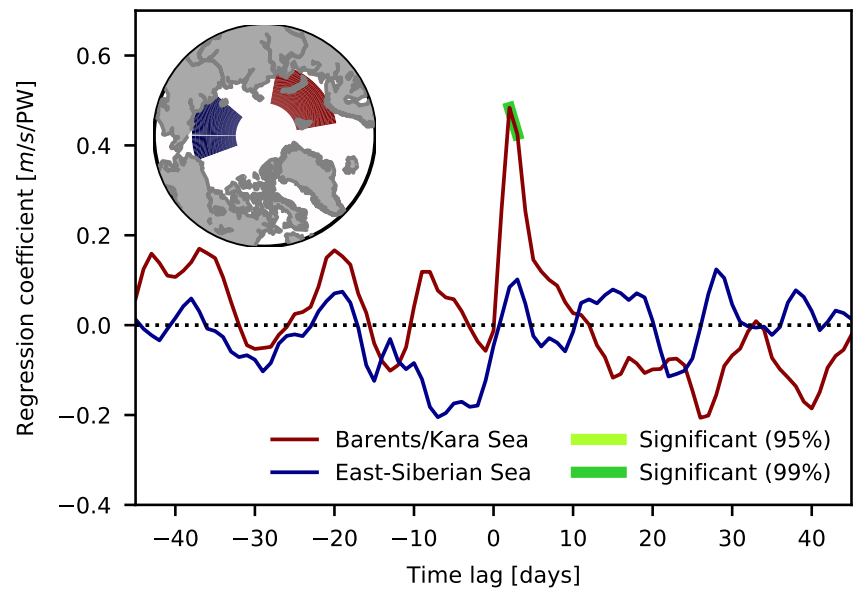

b) Pacific, LWS + SSH + SLH

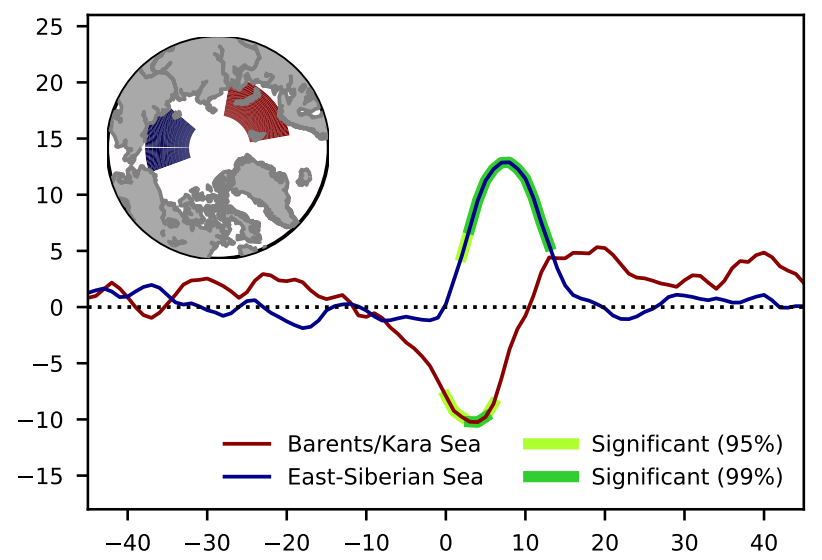

d) Pacific, $10 \mathrm{~m}$ wind

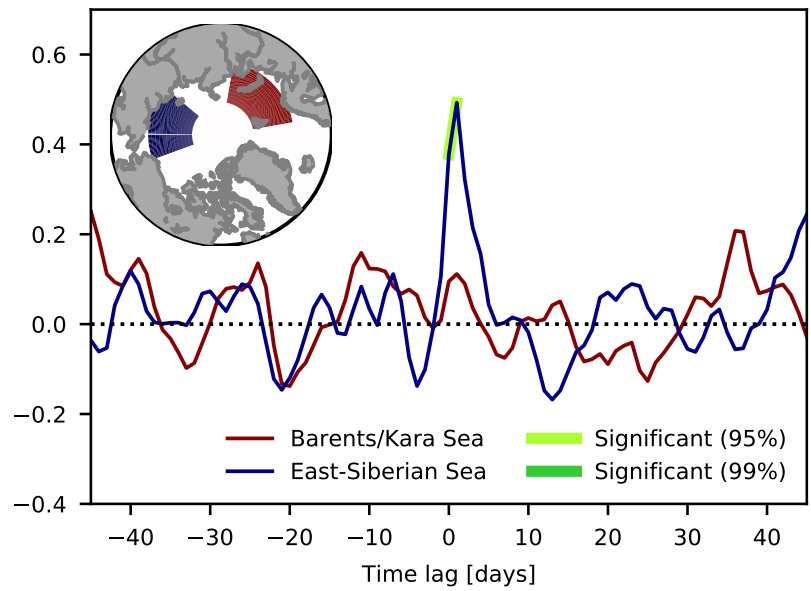

Fig. 9 As Fig. 8, but for regressions over the (a, b) LWS+SSH+SLH, and (b, c) $10 \mathrm{~m}$ wind on the (a, c) Atlantic, and (b, c) Pacific sector planetary latent energy transport across $70^{\circ} \mathrm{N}$.
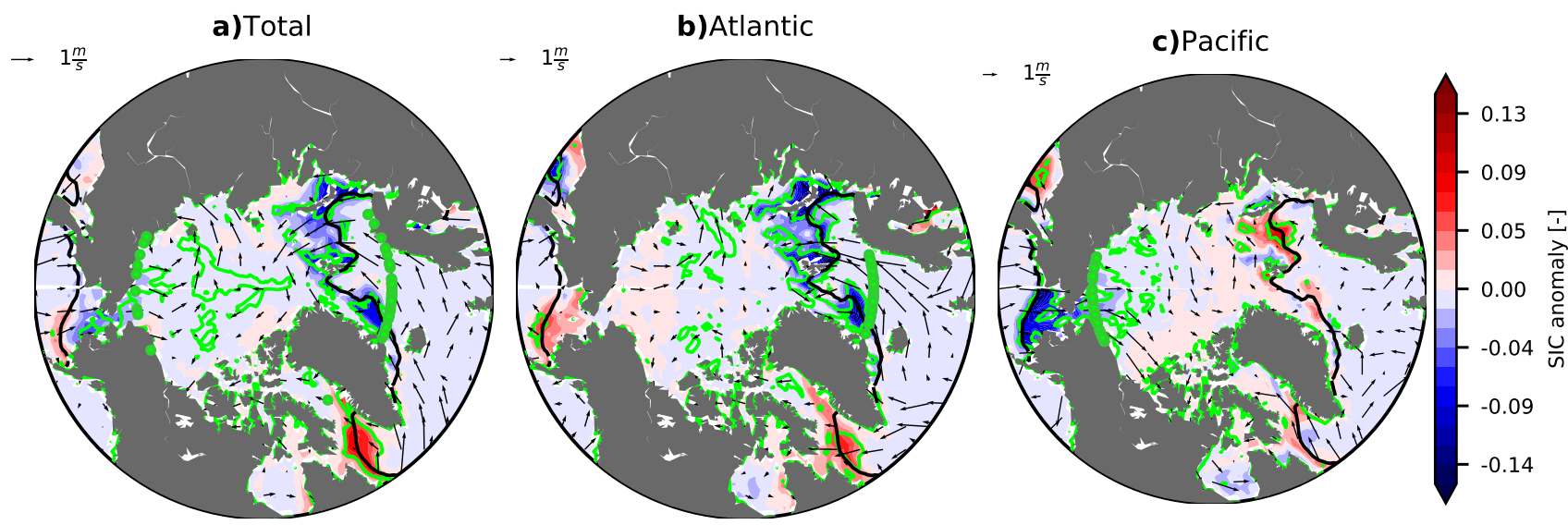

Fig. 10 Composites of SIC and wind anomalies for planetary latent transport extreme events $(>97.5$ th percentile) at lag 5 days after the event maximum for winter (December-February). Green dots along $70^{\circ} \mathrm{N}$ indicate the location of the maximum transport of each extreme event, based on (a) all longitudes, and over the (b) Atlantic and (c) Pacific sectors defined as from $30^{\circ} \mathrm{W}$ to $30^{\circ} \mathrm{E}$ and from $145^{\circ} \mathrm{W}$ to $160{ }^{\circ} \mathrm{E}$, respectively. Anomalies are relative to a climatology over 1979-2018. Shading indicates SIC anomalies, vectors show $10 \mathrm{~m}$-wind anomalies in $\mathrm{m} / \mathrm{s}$, and green contours encapsulate areas where SIC anomalies are significant on a $99 \%$ level based on a Monte-Carlo approach with 5000 simulations. 


\section{a) LWSD}

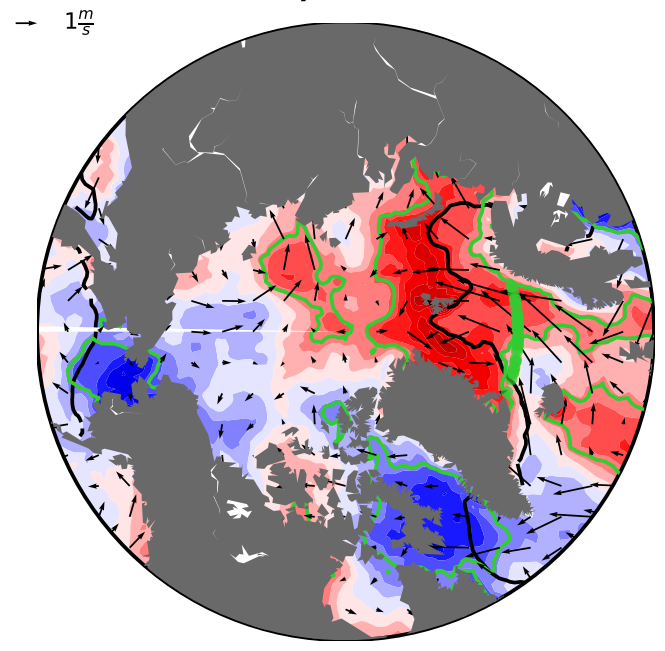

c) $\mathrm{SSH}$

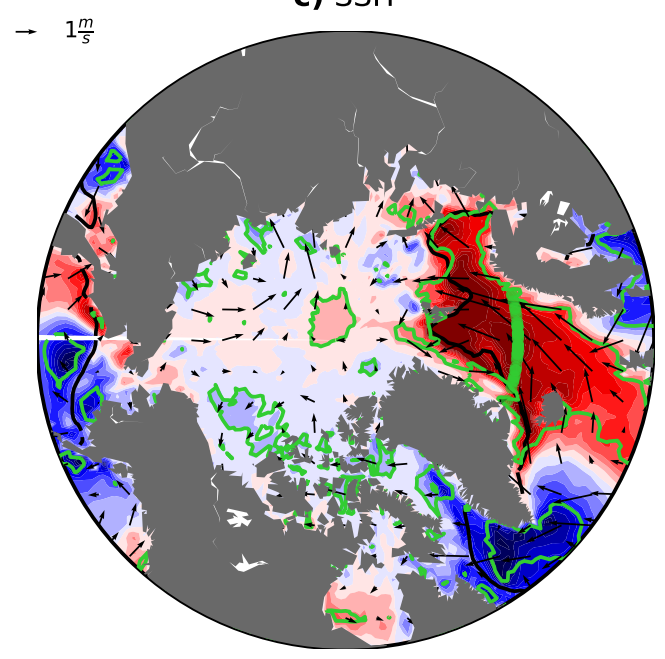

b) LWS

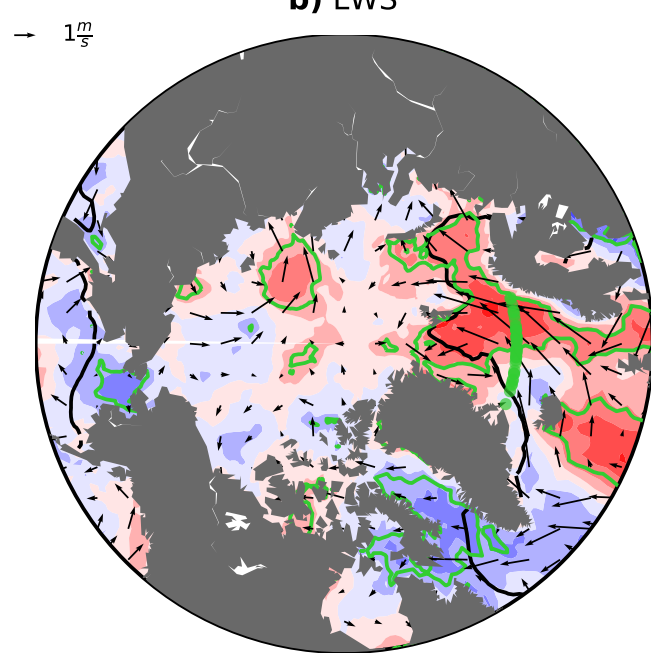

d) SLH

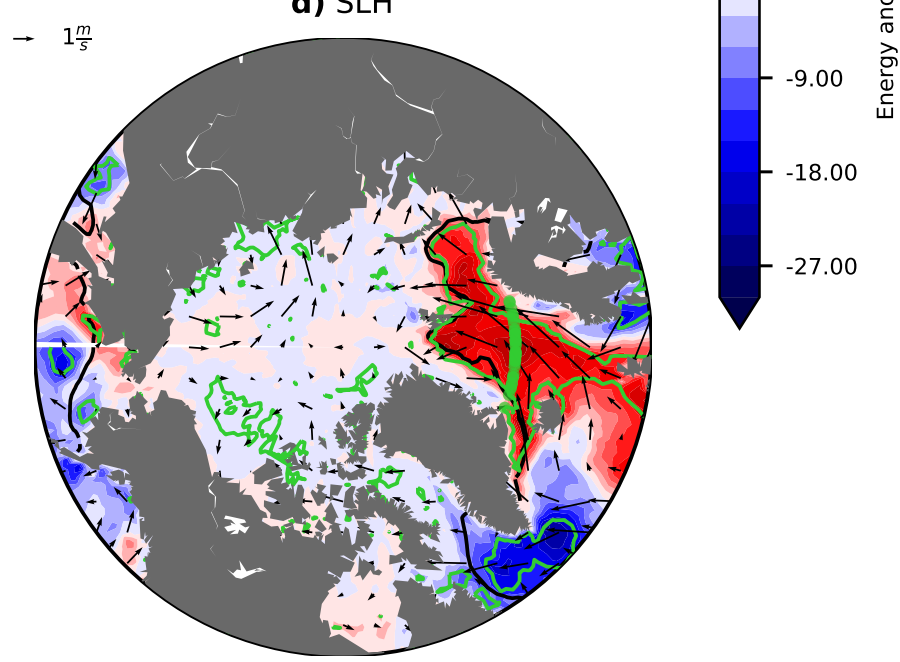

Fig. 11 As Fig. 10b, but for surface (a) down-welling longwave radiation, (b) net longwave radiation, (c) latent heat flux, and (d) sensible heat flux anomalies.

fined to the Atlantic and Pacific sectors, with the former sector being the dominating (Fig. 10a). Hence, the composite over all extremes is dominated by the Atlantic pattern.

In summary, extremes of latent planetary-wave transport during winter most often occur in one of the the two ocean sectors. The transport extremes likely lead to a trans-Arctic flow causing a convergence of humidity, a positive surface energy balance, and a negative ice anomaly at the poleward branch of the transport, and the opposite at the southward transport branch at the other side of the North Pole. In addition, also a dynamical effect of increased surface winds plays a role for the ice response just north of the Arctic entrance of the extreme events.

The summer season shows a similar pattern as compared to winter with regard to negative ice anomalies north of the sector of extreme-transport entrance, and positive anomalies at the other side of the Arctic (Fig. 12b). However in the summer, when the ice is generally thinner, surface winds likely play an even larger role for the ice response due to large-scale drift. Extreme transport events through the Atlantic sector cause cyclonic wind anomalies over the central Arctic, which presumably play an important role in piling up the sea ice in the Beaufort, Chukchi and East-Siberian Seas (Fig. 12b). The piling-up effect down-stream of the Pacific transports is seen only in the Laptev Sea and is less likely to occur at the Atlantic side of the 

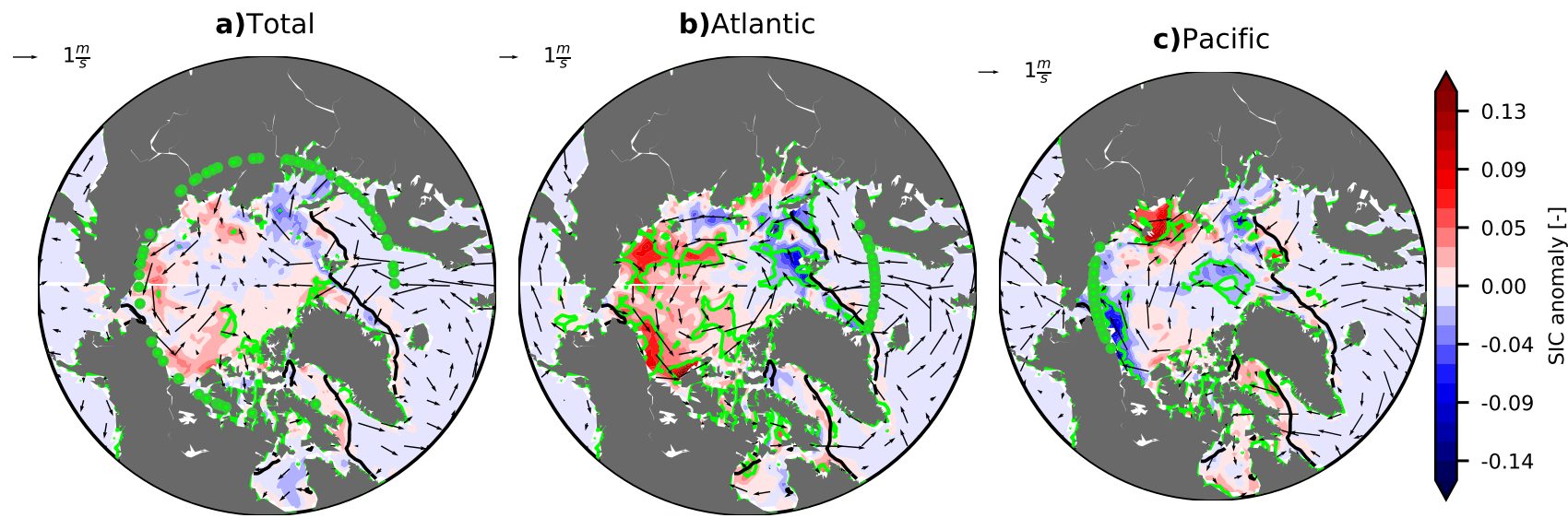

Fig. 12 As Fig. 10, but for the summer season (June-August)

Arctic ocean, where more open pathways to southern latitudes are found, and sea ice is lost due to transport through the Fram strait (Fig. 12c). From Fig. 12a it is indicated that transport extremes in summer are less confined to the Atlantic and Pacific sectors, than is the case for the winter conditions, but occur also over the continents.

\section{Discussion}

Planetary and synoptic-scale waves are strongly characterizing the weather for many of us living in the midlatitudes. Whereas cyclones in many cases bring windy and rainy weather that often last for an afternoon or a day, the large-scale waves are associated with warm or cold and rainy or sunny conditions sustaining for weeks, for instance associated with blocking events. The planetary waves induced by e.g. topography and land-sea heating contrasts meander with varying amplitude and zonal phase speed bringing warm and humid air northward at some latitudes and cold and dry air southward at others. The large-scale nature of these waves implies that a northward flank during strong events can reach large parts of the Arctic where wave breaking in form of convergence of heat and moisture can take place. Cyclones on the other hand are smaller in nature and induced by baroclinic instability where the large-scale meriodional temperature gradient is an important driving force. Hence strong cyclones event predominantly occur during cold Arctic conditions, and their Arctic impact is limited by their spatial scales.

Baggett and Lee (2015) presented interesting work along these lines and showed based on the Lorenz energy cycle frame work that while strong eddy kinetic energy on the synoptic scale is proceeded by enhanced zonal-mean available potential energy, consistent with a strong meriodional temperature gradient, the eddykinetic energy on the planetary scale shows no such dependence. Both types of waves lead to a decrease in the zonal-mean available potential energy, consistent with Arctic warming. They also found that the Arctic warming effect is considerably larger for the planetary than for the synoptic waves. These findings are supported by Graversen and Burtu (2016) and Rydsaa et al. (2021), and are consistent with our results suggesting that planetary waves have a much stronger effect on Arctic sea ice than have cyclones for the same amount of energy transported by the two types of waves. Other studies have earlier pointed to the importance of cyclones and change in "storm tracks" when it comes to the impact on Arctic climate and weather from atmospheric circulation (Woods et al., 2013; Shaw et al., 2016; Schlichtholz, 2018; Nygård et al., 2019). However, this does not necessarily imply a discrepancy between these studies and our results as well as other studies arguing for the larger importance of planetary waves as compared to those of the synoptic scale type: "Storm tracks" which can be regarded as a cyclone wave guide may be just part of Rossby wave. The baroclinic zone at the boundary between polar and subtropical air masses also constitutes the Rossby waves, and cyclones generated here are advected by these planetary waves. Hence many of the phenomena discussed in the studies mentioned above, arguing for the importance of the cyclones, may be coinciding with, and part of planetary-wave transport. This is in agreement with Papritz and Dunn-Sigouin (2020) finding that cyclones play a large role for the moisture transport to the Arctic, but that this transport is found on the planetary scales since blockings on these scales act as a wave guide for the cyclones. 
Consistent with earlier studies, we find that latent transport as compared to the dry-static has a much larger effect on Arctic climate for the same amount of energy transported (Woods et al., 2013; Graversen and Langen, 2019). However the variability of the dry-static transport is an order of magnitude larger than that of the latent, implying that the two types of energy transport show impact on the sea ice of similar magnitude. This is consistent with Olonscheck et al. (2019) finding that moist-static energy is important for Arctic sea-ice variability. However when it comes to model estimation of future trends of Arctic impact by circulation changes, Graversen and Langen (2019) showed that although the dry-static transport decreases more than the latent increases, the total response is still Arctic warming due to a stronger warming potential of the latent as compared to the dry-static component.

\section{Conclusion}

In this study we show the impact of latent as well as dry-static atmospheric energy transport on the Arctic sea ice cover. By analysing regressions of sea-ice anomalies on anomalies in the transport components of both planetary and synoptic scale waves we come to the following conclusions:

- Latent planetary energy transport results in a stronger decrease in sea ice per unit of energy transported as compared to the dry-static component of the transport;

- Due to the larger variability in dry-static planetary transport, the actual impact of dry-static transport on the Arctic sea ice is comparable in magnitude as compared to latent transport;

- The impact of synoptic-scale waves on the Arctic sea ice is considerably smaller than that of the planetary waves. Positive regressions indicate that synopticscale waves occur during cold Arctic conditions;

- Winter extreme transport events occur often either over the Atlantic or over the Pacific sector, resulting in decreased ice conditions in the nearby regions and increased ice conditions in regions on the opposite site of the Arctic.

\section{Funding}

This work was funded by the The Research Council of Norway (NFR) under the project "The role of the atmospheric energy transport in recent Arctic climate change" (no. 280727).

\section{Conflicts of interests}

The authors have no conflicts of interest to declare that are relevant to the content of this article.

\section{3}

784

\section{Code and data availability}

Data and scripts used for this work are stored at the 786 Nird storage facility provided by the Norwegian e-infrastruedure for research and education, UNINETT Sigma2. Data 788 can be accessed on request to the corresponding author.

\section{Authors' contribution}

M. G. Hofsteenge performed most of the data processing and analyses. R. G. Graversen calculated the ERA5 energy transport. M. G. Hofsteenge and R. G. Graversen wrote the paper with input from all co-authors. All authors discussed results and contributed with ideas.

Acknowledgements We thank the ERA5 development group 797 for providing the publicly accessible data on the ECMWF 798 server that was used in this study. The data was processes on the Stallo and Fram supercomputer and stored at the Nird storage facilities provided by the Norwegian e-infrastructure for research and education, UNINETT Sigma2, under the projects NN9348K and NS9063K. This work was funded by the The Research Council of Norway (NFR) under the project "The role of the atmospheric energy transport in recent Arctic climate change" (no. 280727).

\section{References}

Årthun M, Eldevik T, Smedsrud LH, Skagseth, Ingvaldsen RB (2012) Quantifying the influence of Atlantic heat on Barents sea ice variability and retreat. Journal of Climate 25(13):4736-4743, DOI 10.1175/JCLID-11-00466.1

Baggett C, Lee S (2015) Arctic warming induced by tropically forced tapping of available potential energy and the role of the planetary-scale waves. Journal of the Atmospheric Sciences 72(4):1562-1568, DOI 10.1175/JAS-D-14-0334.1

Baggett C, Lee S, Feldstein S (2016) An investigation of the presence of atmospheric rivers over the North Pacific during planetary-scale wave life cycles and their role in Arctic warming. Journal of the Atmospheric Sciences 73(11):4329-4347, DOI 10.1175/JAS-D-160033.1

Boisvert LN, Petty AA, Stroeve JC (2016) The impact of the extreme winter 2015/16 Arctic cyclone 
on the Barents-Kara Seas. Monthly Weather Review 144, DOI 10.1175/MWR-D-16-0234.s1

Döscher R, Koenigk T (2013) Arctic rapid sea ice loss events in regional coupled climate scenario experiments. Ocean Science 9(2):217-248, DOI 10.5194/os9-217-2013

Fox-Kemper B, Hewitt H, Xiao C, Aalgeirsdóttir G, Drijfhout S, Edwards T, Golledge N, Hemer M, Kopp R, Krinner G, Mix A, Notz D, Nowicki S, Nurhati S, Ruiz L, Sallée JB, Slangen A, Yu Y, R E Kopp GK (2021) Ocean, Cryosphere and Sea Level Change. In: MassonDelmotte V, Zhai P, Pirani A, Connors SL, Péan C, Berger S, Caud N, Chen Y, Goldfarb L, Gomis MI, Huang M, Leitzell K, Lonnoy E, Matthews JBR, Maycock TK, Waterfield T, Yelekçi O, Yu R, Zhou B (eds) Climate Change 2021: The Physical Science Basis. Contribution of Working Group I to the Sixth Assessment Report of the Intergovernmental Panel on Climate Change, Cambridge University Press

Graham RM, Itkin P, Meyer A, Sundfjord A, Spreen G, Smedsrud LH, Liston GE, Cheng B, Cohen L, Divine D, Fer I, Fransson A, Gerland S, Haapala J, Hudson SR, Johansson AM, King J, Merkouriadi I, Peterson AK, Provost C, Randelhoff A, Rinke A, Rösel A, Sennéchael N, Walden VP, Duarte P, Assmy P, Steen H, Granskog MA (2019) Winter storms accelerate the demise of sea ice in the Atlantic sector of the Arctic Ocean. Scientific Reports 9(1), DOI 10.1038/s41598019-45574-5

Graversen RG (2006) Do changes in the midlatitude circulation have any impact on the Arctic surface air temperature trend? Journal of Climate 19:5422-5438 Graversen RG, Burtu M (2016) Arctic amplification enhanced by latent energy transport of atmospheric planetary waves. Quarterly Journal of the Royal Meteorological Society 142(698):2046-2054, DOI 10.1002/qj.2802

Graversen RG, Langen PL (2019) On the role of the atmospheric energy transport in $2 \times 3 \mathrm{CO} 2$-induced polar amplification in CESM1. Journal of Climate 32(13):3941-3956, DOI 10.1175/JCLI-D-18-0546.1

Graversen RG, Mauritsen T, Drijfhout S, Tjernström M, Mårtensson S (2011) Warm winds from the Pacific caused extensive Arctic sea-ice melt in summer 2007. Climate Dynamics 36(11-12):2103-2112, DOI $10.1007 / \mathrm{s} 00382-010-0809-\mathrm{z}$

Hegyi BM, Taylor PC (2018) The unprecedented 2016-2017 Arctic sea ice growth season: The crucial role of atmospheric rivers and longwave fluxes. Geophysical Research Letters 45(10):5204-5212, DOI 10.1029/2017GL076717
Heiskanen T, Graversen RG, Rydsaa JH, Isachsen PE (2020) Comparing wavelet and Fourier perspectives on the decomposition of meridional energy transport into synoptic and planetary components. Quarterly Journal of the Royal Meteorological Society DOI 10.1002/qj.3813

Hersbach H, Bell B, Berrisford P, Hirahara S, Horányi A, Muñoz-Sabater J, Nicolas J, Peubey C, Radu R, Schepers D, Simmons A, Soci C, Abdalla S, Abellan X, Balsamo G, Bechtold P, Biavati G, Bidlot J, Bonavita M, De Chiara G, Dahlgren P, Dee D, Diamantakis M, Dragani R, Flemming J, Forbes R, Fuentes M, Geer A, Haimberger L, Healy S, Hogan RJ, Hólm E, Janisková M, Keeley S, Laloyaux P, Lopez P, Lupu C, Radnoti G, de Rosnay P, Rozum I, Vamborg F, Villaume S, Thépaut JN (2020) The ERA5 global reanalysis. Quarterly Journal of the Royal Meteorological Society 146(730):1999-2049, DOI 10.1002/qj.3803

Hirahara S, Alonso-Balmaseda M, de Boisseson E, Hersbach H (2016) Sea surface temperature and sea ice concentration for ERA5 - ECMWF. In: ERA Report Series No. 26

Kapsch ML, Graversen RG, Tjernström M (2013) Springtime atmospheric energy transport and the control of Arctic summer sea-ice extent. Nature Climate Change DOI 10.1038/nclimate1884

Kapsch ML, Graversen RG, Tjernström M, Bintanja R (2016) The effect of downwelling longwave and shortwave radiation on Arctic summer sea ice. Journal of Climate 29(3):1143-1159, DOI 10.1175/JCLI-D-150238.1

Kapsch ML, Skific N, Graversen RG, Tjernström M, Francis JA (2019) Summers with low Arctic sea ice linked to persistence of spring atmospheric circulation patterns. Climate Dynamics 52(3-4):2497-2512, DOI 10.1007/s00382-018-4279-z

Kashiwase H, Ohshima KI, Nihashi S, Eicken H (2017) Evidence for ice-ocean albedo feedback in the Arctic Ocean shifting to a seasonal ice zone. Scientific Reports 7(1), DOI 10.1038/s41598-017-08467-z

Kay JE, L'Ecuyer T (2013) Observational constraints on Arctic Ocean clouds and radiative fluxes during the early 21st century. Journal of Geophysical Research Atmospheres 118(13):7219-7236, DOI 10.1002/jgrd.50489

Kay JE, L'Ecuyer T, Gettelman A, Stephens G, O'Dell C (2008) The contribution of cloud and radiation anomalies to the 2007 Arctic sea ice extent minimum. Geophysical Research Letters 35(8), DOI 10.1029/2008GL033451

Liu Z, Schweiger A (2017) Synoptic conditions, clouds, and sea ice melt onset in the Beaufort and Chukchi 
seasonal ice zone. Journal of Climate 30(17):69997016, DOI 10.1175/JCLI-D-16-0887.1

Mills CM, Walsh JE (2014) Synoptic activity associated with sea ice variability in the Arctic. Journal of Geophysical Research 119(21):117-12, DOI 10.1002/2014JD021604

Mortin J, Svensson G, Graversen RG, Kapsch ML, Stroeve JC, Boisvert LN (2016) Melt onset over Arctic sea ice controlled by atmospheric moisture transport. Geophysical Research Letters 43(12):66366642, DOI 10.1002/2016GL069330

Nygård T, Graversen RG, Uotila P, Naakka T, Vihma T (2019) Strong dependence of wintertime Arctic moisture and cloud distributions on atmospheric largescale circulation. Journal of Climate 32(24):87718790, DOI 10.1175/JCLI-D-19-0242.1

Ogi M, Yamazaki K, Wallace JM (2010) Influence of winter and summer surface wind anomalies on summer Arctic sea ice extent. Geophysical Research Letters 37(7):-, DOI 10.1029/2009GL042356

Olonscheck D, Mauritsen T, Notz D (2019) Arctic sea-ice variability is primarily driven by atmospheric temperature fluctuations. Nature Geoscience 12(6):430-434, DOI 10.1038/s41561-019-0363-1

Onarheim IH, Eldevik T, Smedsrud LH, Stroeve JC (2018) Seasonal and regional manifestation of Arctic sea ice loss. Journal of Climate 31(12):4917-4932, DOI 10.1175/JCLI-D-17-0427.1

Papritz L, Dunn-Sigouin E (2020) What configuration of the atmospheric circulation drives extreme net and total moisture transport into the Arctic. Geophysical Research Letters 47(17), DOI 10.1029/2020GL089769

Park HS, Lee S, Feldstein SB, Kosaka YU (2015) The impact of poleward moisture and sensible heat flux on Arctic winter sea ice variability. Journal of Climate 28:5030-5040, DOI 10.1175/JCLI-D-15

Parkinson CL, Cavalieri DJ (2008) Arctic sea ice variability and trends, 1979-2006. Journal of Geophysical Research: Oceans 113(7):7003, DOI 10.1029/2007JC004558

Peng G, Meier WN (2018) Temporal and regional variability of Arctic sea-ice coverage from satellite data. Annals of Glaciology 59(76pt2):191-200, DOI 10.1017/aog.2017.32

Rydsaa J, Graversen R, Heiskanen TIH, Stoll PJ (2021) Changes in atmospheric latent energy transport into the Arctic; planetary versus synoptic scales. Quarterly Journal of the Royal Meteorological Society $\mathrm{p}$ qj.4022, DOI 10.1002/qj.4022

Schlichtholz P (2018) Climate impacts and Arctic precursors of changing storm track activity in the Atlantic-Eurasian region. Scientific Reports 2018 8:1
8(1):1-19, DOI 10.1038/s41598-018-35900-8

Schweiger AJ, Zhang J, Lindsay RW, Steele M (2008)

Did unusually sunny skies help drive the record sea ice minimum of 2007? Geophysical Research Letters 35(10), DOI 10.1029/2008GL033463

Screen JA, Simmonds I, Keay K (2011) Dramatic interannual changes of perennial Arctic sea ice linked to abnormal summer storm activity. Journal of Geophysical Research Atmospheres 116(15), DOI 10.1029/2011JD015847

Serreze MC, Stroeve J (2015) Arctic sea ice trends, variability and implications for seasonal ice forecasting. Philosophical Transactions of the Royal Society A: Mathematical, Physical and Engineering Sciences 373(2045), DOI 10.1098/rsta.2014.0159

Serreze MC, Box JE, Barry RG, Walsh JE (1993) Characteristics of Arctic synoptic activity, 1952-1989. Meteorology and Atmospheric Physics 51(3-4):147-164, DOI 10.1007/BF01030491

Shaw TA, Baldwin M, Barnes EA, Caballero R, Garfinkel CI, Hwang YT, Li C, O'Gorman PA, Rivière G, Simpson IR, Voigt A (2016) Storm track processes and the opposing influences of climate change. Nature Geoscience 2016 9:9 9(9):656-664, DOI 10.1038/ngeo2783

Simmonds I, Rudeva I (2012) The great Arctic cyclone of August 2012. Geophysical Research Letters 39(23), DOI 10.1029/2012GL054259

Trenberth KE (1991) Climate diagnostics from global analyses: Conservation of mass in ECMWF analyses. Journal of Climate 4(7)

Wang Z, Walsh J, Szymborski S, Peng M (2020) Rapid Arctic sea ice loss on the synoptic time scale and related atmospheric circulation anomalies. Journal of Climate 33:1597-1617, DOI 10.1175/JCLI-D-19

Woods C, Caballero R (2016) The role of moist intrusions in winter arctic warming and sea ice decline. Journal of Climate 29(12):4473-4485, DOI 10.1175/JCLI-D-15-0773.1

Woods C, Caballero R, Svensson G (2013) Large-scale circulation associated with moisture intrusions into the Arctic during winter. Geophysical Research Letters 40(17):4717-4721, DOI 10.1002/grl.50912

Yang W, Magnusdottir G (2017) Springtime extrememoisture transport into the Arctic and its impact on sea ice concentration. Journal of Geophysical Research 122(10):5316-5329, DOI 10.1002/2016JD026324

Zhang J, Lindsay R, Schweiger A, Steele M (2013) The impact of an intense summer cyclone on 2012 Arctic sea ice retreat. Geophysical Research Letters 40(4):720-726, DOI 10.1002/grl.50190

Zhang X, Walsh JE, Zhang J, Bhatt US, ${ }_{1035}$ Ikeda M (2004) Climatology and interan- 1036 
${ }_{1037}$ nual variability of Arctic cyclone activity:

1038 1948-2002. Journal of Climate 17(12):2300-

$10392317, \quad$ DOI https://doi.org/10.1175/1520-

$1040 \quad$ 0442(2004)017¡2300:CAIVOA ¿2.0.CO;2 